\title{
PROPOSTA DE FORMAÇÃO DOCENTE PARA/ NA CONSECUÇÃO DE PRÁTICAS PEDAGÓGICAS INCLUSIVAS: A FORESPI EM MOVIMENTO
}

\author{
TEACHER TRAINING PROPOSAL FOR / IN ACHIEVING INCLUSIVE PEDAGOGICAL \\ PRACTICES: FORESPI IN MOVEMENT
}

\author{
PROPUESTA DE FORMACIÓN DOCENTE PARA/EN EL LOGRO DE PRÁCTICAS \\ PEDAGÓGICAS INCLUSIVAS: LA FORESPI EN MOVIMIENTO
}

Marcia Torres Neri Soares

E-mail: profa.marciatorres@gmail.com

Adarita Souza da Silva \begin{abstract}
E-mail: adaritasouzadasilva3@gmail.com
RESUMO

Este texto objetiva apresentar um corpus teórico acerca da formação docente (IMBERNÓN, 2005) e o desafio da inclusão escolar (BUENO, 2008; LAPLANE, 2004) à luz da proposta denominada Formação Continuada para Estudos em Educação Especial na perspectiva inclusiva (FORESPi). A formação desenvolvida no ano de 2020 como estratégia de enfrentamento ao período pandêmico provocado pela Covid 19, resultou da iniciativa colaborativa no âmbito da gestão da educação pública de um município baiano com adesão de 105 professores. Realizada por meio da plataforma google meet, a FORESPi totalizou uma carga horária de 50 horas, tendo contemplado temas no trato da inclusão escolar e da concepção de deficiência. Para disposição dos conteúdos, apostou-se na diversidade de estratégias a fim de tornar os encontros mais correspondentes às inspirações teóricometodológicas. Realizou-se lives; minicursos acerca das especificidades pedagógicas das deficiências e encontros denominados Rodas de Conversa. Além disso, contou com o google classroom para enriquecimento curricular da proposta. Foi possível identificar evidências: I. a importância do desenvolvimento de propostas colaborativas no trato da inclusão escolar; II. o relevo ao conhecimento das necessidades formativas docentes; III. a credibilidade atribuída à FORESPi; e a IV. relevância do investimento no âmago das políticas públicas educacionais. Sem a pretensão de ser um compêndio prescritivo à prática docente, o texto é um prenúncio da (re)criação de estratégias para a interlocução com a escola e seus sujeitos, em especial com concepções sobre deficiência e inclusão escolar.
\end{abstract}

PALAVRAS-CHAVE: Formação Docente. Inclusão Escolar. Deficiência.

\section{ABSTRACT}

This text aims to present a theoretical corpus about teacher training (IMBERNÓN, 2005) and the challenge of school inclusion (BUENO, 2008; LAPLANE, 2004) in the light of the proposal called Continuing Education for Studies in Special Education from the inclusive perspective (FORESPi). The training developed in 2020 as a strategy to face the pandemic period caused by Covid-19, resulted from the collaborative initiative in the scope of public education management in a municipality in Bahia with the participation of 105 teachers. Held through the Google Meet platform, FORESPi totaled a workload of 50 hours, covering themes in terms of school inclusion and the concept of disability. For the disposal of the contents, a bet was made on the diversity of strategies to make the meetings more corresponding to the theoretical and methodological inspirations. In this way, live streams were held; mini courses about the pedagogical specificities of the deficiencies and meetings called Talking Circles. In addition, it had access to Google Classroom for curricular enrichment of the proposal. With the study, it was possible to identify evidence: I. the importance of developing collaborative proposals in dealing with school inclusion; II. the emphasis on the knowledge of the teacher training needs; III. the credibility attributed to FORESP ; and IV. relevance of investment at the heart of educational public policies. Without pretending to be a prescriptive compendium for teaching practice, the text is a harbinger of the (re)creation of strategies for dialogue with the school and its subjects, especially with their conceptions about disability and school inclusion. 
KEYWORDS: Teacher training. School inclusion. Disability.

\section{RESUMEN}

Este texto tiene como objetivo presentar un corpus teórico sobre la formación docente (IMBERNÓN, 2005) y el reto de la inclusión escolar (BUENO, 2008; LAPLANE, 2004) a la luz de la propuesta FORESPi. La capacitación desarrollada en 2020 como estrategia para enfrentar el periodo pandémico provocado por la Covid 19, resultó de la iniciativa colaborativa en el ámbito de la gestión de la educación pública en un municipio de Bahía con la participación de 105 docentes. Realizado a través de la plataforma Google Meet, FORESPi totalizó una carga de trabajo de 50 horas, abordando temas en términos de inclusión escolar y el concepto de discapacidad. Para la disposición de los contenidos se apostó por la diversidad de estrategias con el fin de hacer los encuentros más acordes a las inspiraciones teórico-metodológicas. Se realizaron emisiones en directo; minicursos sobre las especificidades pedagógicas de las discapacidades y encuentros denominados Grupos de Conversación. Además, se tuvo acceso a Google Classroom para enriquecimiento curricular de la propuesta. Fue posible identificar estas evidencias: I. la importancia de desarrollar propuestas colaborativas al abordar la inclusión escolar; II. el énfasis en el conocimiento de las necesidades de formación docente; III. la credibilidad atribuida a FORESPi; y IV. la relevancia de la inversión en el núcleo de las políticas públicas educativas. Sin pretender ser un compendio prescriptivo para la práctica docente, el texto es un presagio de la (re)creación de estrategias de diálogo con la escuela y sus sujetos, especialmente con sus concepciones sobre la discapacidad y la inclusión escolar.

PALABRAS-CLAVE: Formación del profesorado. Inclusión escolar. Discapacidad.

\section{INTRODUÇÃO}

A formação docente é tema recorrente, porém não suficientemente enfrentado no campo das políticas públicas educacionais brasileiras (VÓVIO; ALMEIDA, 2019). Ao se tratar de proposições voltadas ao direito à escolarização de estudantes com deficiência, Transtornos Globais do Desenvolvimento e altas habilidades/superdotação ${ }^{1}$ (BRASIL, 2008), comumente é possível ouvir afirmações sobre o despreparo ou um conjunto de necessidades formativas ausentes das formações iniciais de diferentes professores.

A alegação sobre (im)possibilidades na inclusão de estudantes com deficiência muitas vezes vem acompanhada de justificativas sobre o desconhecimento dos aspectos pedagógicos específicos para o atendimento às suas especificidades. Conforme compreendemos, tais aspectos são os mesmos assimilados no trato com quaisquer estudantes, conquanto, devemos oportunizar espaços de discussão para alargar essa compreensão e conversar sobre concepções da deficiência e suas influências no contexto escolar.

Assimilar a relevância de fortalecer tais espaços de discussão contribuiu para a idealização da Formação Continuada para Estudos em Educação Especial na perspectiva inclusiva (FORESPi), com o fito de problematizar a importância e implicações da prática pedagógica no processo de inclusão da criança/estudante com deficiência, entendendo a

\footnotetext{
${ }^{1}$ Neste texto utilizamos o termo pessoas com deficiência como representativo deste público.
} 
relevância de seu papel para participação e desenvolvimento no bojo da unidade educacional, assim como na ampliação da rede de apoio à inclusão da educação pública municipal.

Desse modo, o presente texto tem por objetivo apresentar um corpus teórico acerca da formação docente e o desafio da inclusão escolar à luz da proposta denominada FORESPi, porque inconteste pode iluminar, face às análises partilhadas neste estudo, outras experiências/pesquisas com o fulcro nas potencialidades de diferentes estudantes e nas ricas possibilidades de diálogos com os professores, os quais lidam com propostas inclusivas no interior de suas concepções e práticas.

A FORESPi, objeto de estudo a ser divulgado neste manuscrito, fruto do esforço coletivo de professoras da rede municipal de Feira de Santana-BA ${ }^{2}$, foi engendrada durante o ano de 2020, como estratégia de chegar aos professores dessa instância municipal, mediada por recursos tecnológicos durante a pandemia da Covid 19 e a consequente interrupção das aulas presenciais e distanciamento social. Operacionalizada entre os meses de agosto à dezembro, sua realização obedeceu a elaboração de um projeto, conforme compartilhado neste texto.

Para fins de organização, além desta seção introdutória, o texto apresenta seu referencial teórico em Formação docente, inclusão escolar e deficiência: alicerces teóricos para a gênese da FORESPi. Sob o entendimento norteador desta construção, concepções teóricas são demasiadamente importantes para o modo de (re)configuração das práticas curriculares em contato com estudantes com deficiência. Em seguida, compartilhamos os Bastidores da FORESPi: planejamento, metodologia e resultados com a intenção de socializar as principais discussões do estudo em termos de idealização e implementação à luz das condições enfrentadas no espaço educacional em tela. Feito isto, realçamos nossas Considerações Finais à guisa de assinalar a continuidade do diálogo com outros interessados e estudiosos no campo da Educação Especial/Inclusiva. Havendo explicitado o fio condutor da discussão pretendida, doravante apresentamos as confluências teóricas de sustentação do presente texto.

\section{Formação docente, inclusão escolar e deficiência: alicerces teóricos para a gênese da FORESPi}

\footnotetext{
${ }^{2}$ Em princípio, a iniciativa foi idealizada por duas professoras do órgão gestor governamental, autoras deste artigo. Posteriormente, professoras de Salas de Recursos Multifuncionais foram convidadas, agregaram a proposta com valiosas contribuições ao projeto e participação nos encontros formativos.
} 
A discussão ensejada nesta seção parte do princípio sobre ser indispensável o aporte teórico na/para os diálogos pretendidos. Para tanto, principiamos pelo entendimento da formação docente e suas nuances no campo da inclusão escolar. Nesse sentido, embora a inclusão escolar compreenda condições de participação de quaisquer estudantes em situação de vulnerabilidade, neste estudo, tomamos por base as condições de participação de estudantes com deficiência, conforme apresentado à introdução do texto.

Segundo compreendemos, a inclusão escolar reflete uma tomada de decisão no trato do respeito às diferenças, ou em outras palavras, a "inclusão escolar refere-se a uma proposição política em ação, de incorporação de alunos que tradicionalmente têm sido excluídos da escola, [enquanto que a] educação inclusiva refere-se a um objetivo político a ser alcançado". (BUENO, 2008, p. 49).

A atualidade do tema e sua aderência ao desenvolvimento das práticas pedagógicas docentes, bem como a perspectiva de entendimento dessa proposição política em ação, nos moldes assinalados pelo autor, transversalizam nosso debate. Outrossim, Gaudezin e Ortega (2016) demarcam a permanência do tema da inclusão escolar até os dias atuais em decorrência das condições (ou a falta destas) para viabilização da participação de pessoas com deficiência na sociedade.

Desse modo, compreender a formação docente como parte de uma política educacional foi condição primordial para o desenvolvimento da proposta. Em um sentido amplo, "a ausência de referências às principais causas da desigualdade cria a ilusão de que a educação as gera e, consequentemente, de que a mudança nas formas de organização dos sistemas de ensino pode, sozinha, revertê-las" (LAPLANE, 2004, p. 17). É preciso inserir o debate e inquiri-lo conforme os acordos na consecução desta política (PAIVA; BENDASSOLLI, 2017).

Há, portanto, uma tendência em separar os conteúdos da educação especial e desvinculá-los, de maneira reducionista, do contexto da educação geral com todas suas complexidades e incoerências (FERREIRA; FERREIRA, 2004). As problematizações decorrentes deste texto cooperam para o entendimento da política pública de inclusão no cerne de sua inserção social porque "a educação, como qualquer política social, é também fruto de luta da sociedade organizada, (.) [e] não há como entender o movimento de lutas desvinculadas do movimento da sociedade" (KASSAR, 2004, p. 64). 


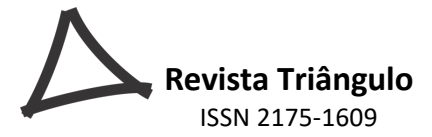

Notadamente, a intersecção de forças, neste manuscrito separadas em dois eixos, tanto no: A) entendimento da vinculação dos aspectos inerentes a inclusão escolar como genuinamente ligados ao contexto macro das políticas educacionais em vigor, quanto na B) compreensão de suas convergências para o respeito ao ser com deficiência em sua totalidade, numa visão global de suas capacidades e das condições de participação facultadas, ajudou a consubstanciar a argumentação em favor da ideia do movimento de lutas em prol da garantia dos direitos das pessoas com deficiência deve assumir vigilância em nossas concepções e ações, afinal:

[...] a abordagem do tema não deve ser isolada, no discurso de garantias de direitos para as pessoas com deficiência, pois ele compreende não só garantia à saúde, à educação e ao trabalho em condições dignas, mas ainda garantia à vida ou a todos os requisitos de respeito à vida. Essa tarefa compete, pois, não só aos governos, mas a todos os atores sociais engajados na luta pelos direitos dos cidadãos, sejam eles marcados ou não pelo estigma da deficiência. (PAIVA; BENDASSOLLI, 2017, p. 427).

Reiteradamente, face ao eixo A, não podemos idealizar uma proposta de formação continuada negando as condições de trabalho docente em sua conjuntura mais ampla. No cenário brasileiro, nota-se um interesse pelo campo de estudos, em especial, dos temas relativos à constituição de identidade, profissionalização e trabalho docente sob diferentes enfoques (VÓVIO; ALMEIDA, 2019; DINIZ-PEREIRA, 2013).

Além disso, precisamos insistir na moldura base de sua assunção epistemológica, afinal a ausência de uma política global de valorização e formação dos profissionais de educação sob a interlocução constante entre formação inicial, continuada e condições de trabalho e, ainda, concepção sócio histórica, ainda é uma utopia (FREITAS, 2007).

Acresça-se a problemática, a desconexão entre conhecimentos acadêmicos e a dimensão prática da formação, pois "na realidade brasileira, muito embora possamos reconhecer que existe um esforço das instituições que formam os professores em modificar essa realidade, esse parece ser ainda um desafio a ser enfrentado" (NASCIMENTO; REIS, 2017, p. 53). Obter correspondência às práticas docentes, sem prescindir do rigor teórico, subjaz propostas formativas condescendentes com as realidades concretas de escolas e práticas pedagógicas.

Nesse sentido, do ponto de vista da vertente política, uma proposta de formação continuada requer considerar aspectos concernentes às condições de desenvolvimento e aderência no âmbito de uma rede municipal, tal como intentamos realizar durante a operacionalização da FORESPi. 


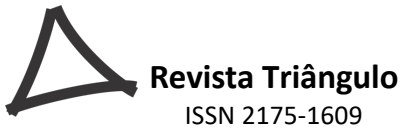

Não obstante, a superação da visão empobrecida e ensimesmada da formação docente povoou nossas preocupações, afinal "neste sentido, mesmo não havendo clareza no conceito de formação continuada ela deve ser entendida como uma permanente" (SILVEIRA; CASTAMAN, 2020, p. 7). Entender a imprescindibilidade de investimento contínuo, pois assim se definem os conteúdos no campo educacional, serviu de força motriz aos desdobramentos da FORESPi.

O eixo B: "compreensão de suas convergências (da inclusão escolar) para o respeito ao ser com deficiência em sua totalidade, numa visão global de suas capacidades e das condições de participação facultadas", exigiu-nos dialogar acerca das concepções de deficiência, afinal estas parecem ser determinantes paras as práticas pedagógicas desenvolvidas, se assistencialistas ou prospectivas, se baseadas no anulamento às condições de participação dos sujeitos ou na promoção de sua autonomia.

Dessa forma, outro aspecto caro à discussão pretendida delimitou-se pelas concepções harmonizadas desde a elaboração do projeto à sua implementação. Como já circunscrevemos as concepções de inclusão escolar e formação docente de alicerce desse projeto, convém também elucidar qual entendimento da deficiência serviu como determinante para sua formulação.

O modelo social da deficiência passou a explicá-la como experiência de desigualdade compartilhada por pessoas de distintos impedimentos, cuja diversidade de corpos abriga uma variedade de formas de habitação desse mesmo corpo (DINIZ; BARBOSA; SANTOS, 2009). Essa explicação adquiriu notável mudança na forma de olhar para a deficiência e exigiu um exercício de revisitar práticas cristalizadas no ambiente escolar.

\footnotetext{
Admitir que a deficiência não é uma questão relacionada apenas ao corpo físico, pode ser considerado um avanço, sobretudo por permitir pensá-la a partir de uma discussão interdisciplinar, o que possibilita estudar questões mais amplas, como: sexo, idade, cultura, entre diversos outros fatores que possam ampliar as discussões acerca de questões inclusivas. (ARAÚJO; CUNHA, 2020, p. 323).
}

A deficiência, desse modo, não é um conceito limitado pela condição física da pessoa, antes se constitui nas interações sociais, pela forma como as condições de vida lhes são apresentadas, ou pelas oportunidades disponíveis. O ser pessoa com deficiência decorre das experiências diárias enfrentadas e das reelaborações fruto destas experiências.

Em 1980, a rejeição ao modelo médico e à ideia de que a deficiência precisa ser "corrigida" ganha força, assim como a defesa de que os "ajustamentos" não deveriam 
ser dos indivíduos deficientes, mas da sociedade, pois ela que era desajustada em relação a estes. Entendia-se que a opressão social e a exclusão dos deficientes não resultavam de suas limitações físico-mentais e que a experiência da desigualdade apenas se manifesta em uma sociedade pouco sensível à diversidade de estilos de vida. Neste contexto, marcado pela "primeira geração" dos acadêmicos e ativistas da deficiência, os estudiosos atentam para a complexidade do conceito de deficiência que, longe de ser sinônimo de um corpo com lesão, também denuncia a estrutura social que oprime a pessoa que apresenta um corpo atípico. Em contraposição ao modelo médico da deficiência, cresce o modelo social da deficiência. (GAUDENZI; ORTEGA, 2016. p. 3063).

Práticas aviltantes de exclusão da deficiência no seio de nossa sociedade coadunaram para lhe imputar um fardo e, a partir dessa "sentença", destituir de condições para sua participação equitativa em sociedade. Abrir espaço para dialogar sobre o tema, alcançou rebatimento na FORESPi e, por isso, também justifica sua relevância para o desenvolvimento de propostas mais condizentes com o respeito às diferenças, aspecto, sob o ponto de vista assumido neste texto, a corroborar com a participação de outros estudantes em situação de desvantagem escolar ou rotulados como inaptos para a aprendizagem. Destarte, "no paradigma da inclusão, impulsionaram-se projetos de mudanças nas políticas públicas brasileiras, ao conceber-se que todos se beneficiam quando as escolas promovem respostas às diferenças individuais dos estudantes" (BARBOSA; FIALHO; MACHADO, 2018, p. 18).

Endossam a relevância da iniciativa, a constatação sobre a insistência do modelo médico e suas repercussões sociais “[...] as ideias de normalizar/renormalizar as pessoas com deficiência não foram extirpadas da sociedade e se mostram presentes no contexto atual." (ARAÚJO; CUNHA, 2020, p. 311). Este é, portanto, conteúdo sine qua non ao se pensar uma proposta formativa voltada ao acompanhamento pedagógico dispensado a esse público. Assim, tendo balizado as acepções teóricas de construção da FORESPi, passamos a compartilhar, do ponto de vista metodológico, suas principais contribuições como realizamos no seguimento.

\section{Bastidores da FORESPi: planejamento, metodologia, resultados}

A FORESPi obedeceu a um projeto de idealização de professoras consideradas autoras da proposta. Suas experiências advindas do trabalho na própria rede municipal, pano de fundo para as discussões pretendidas, colaborou para o alcance das atividades parcialmente compartilhadas neste texto. 


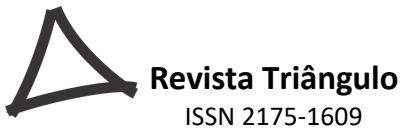

A inquietação das professoras idealizadoras com o acompanhamento pedagógico dos estudantes com deficiência e a possibilidade de oportunizar discussões alicerçadas na perspectiva de uma escola inclusiva, indicavam a carência na formação dos professores da rede como caminho e possibilidade de avanço da qualidade de ensino de forma geral.

O planejamento da FORESPi construído de modo incessante pelos diálogos internos, com as professoras formadoras, sobre os estudos atuais no bojo da educação inclusiva foi fundamental. Tornou-se possível identificar as necessidades formativas, principalmente no tocante às ações para inclusão de todos os estudantes em propostas educativas direcionadas ao contexto da sala de aula.

Para a FORESPi, a estruturação curricular foi projetada em temáticas compatíveis com estratégias políticas e pedagógicas da educação especial com perspectiva inclusiva, proporcionando aos professores cursistas a apropriação dos saberes e partilha de experiências no intuito de ampliar as possibilidades de superação aos desafios postos pela presença do estudante com deficiência na sala de aula comum. Estes professores, um total de $105^{3}$, estiveram distribuídos em 03 turmas a fim de atender a organização didática de discussão dos conteúdos. Dessa forma, as temáticas desenvolvidas durante a formação permitiram tencionar uma linha formativa sem engessar as possibilidades de aprendizagem dos professores cursistas.

O contexto de gênese do planejamento da FORESPi, portanto, primou pela perspectiva de mudança, essencialmente humana. Segundo Vasconcellos (2006), o planejamento apenas faz sentido se o sujeito encontrar-se numa condição de transformação. Nesse sentido, os pressupostos básicos e teóricos da formação assentaram-se em importantes vertentes sob a perspectiva inclusiva, a saber: I. o diálogo com o professor acerca do trabalho pedagógico; II. a discussão dos princípios e fundamentos da Educação Especial; III. os fundamentos teóricos alusivos à temática das deficiências e transtornos; e por fim, IV. a compreensão do currículo como modo de favorecer o processo de ensino e aprendizagem da criança/estudante com deficiência, bem como demais estudantes da turma.

Tais vertentes foram desdobradas em uma estrutura curricular peculiar, conforme aderência com as necessidades formativas dos professores participantes. Estas são doravante apresentadas como possibilidades de diálogos para propostas da educação especial na perspectiva inclusiva: a) a deficiência como produção social e aspectos familiares; b) bases

\footnotetext{
${ }^{3}$ A delimitação do número não obedeceu ao número de professores interessados na rede, antes guiou-se pelo número correspondente de professoras formadoras. Desse modo, muitas solicitações chegaram após a finalização das inscrições, porém não houve possibilidade de ampliação das turmas.
} 
legais da Educação Especial; c) princípios da Educação Especial; d) papel dos sujeitos na escola inclusiva; e) terminologias do público alvo da Educação Especial; f) avaliação, planejamento e procedimentos didático pedagógicos no âmbito da Educação Especial com perspectiva inclusiva; g) a proposta curricular de Educação Especial da rede pública municipal; e h) o trabalho colaborativo na perspectiva da inclusão de estudantes com deficiência: vozes e práticas. Estas temáticas foram desenvolvidas durantes os encontros virtuais quinzenais pelo google meet com acesso ao material alusivo ao curso e interações nos fóruns por meio do google classroom.

Nesse sentido, os encontros, cada um com a carga horária de 3 horas, considerando a hora aula de 40 minutos, foram cuidadosamente planejados para corresponder aos objetivos e pautas. No contexto pandêmico, o horário de realização, sempre ao final da tarde, foi pensado em função da concentração dos afazeres domésticos no turno da manhã, bem como ter sido considerado um horário intermediário para professores com outras ocupações profissionais. A escolha encontrou boa aprovação dos participantes. O desafio residiu em conciliar o curto espaço de tempo sem tornar a formação cansativa, principalmente no formato virtual, e também não esvaziar o nível conceitual e teórico exigido numa proposta dessa natureza.

Permeou a discussão das temáticas o entendimento de sua pertinência com quaisquer estudantes e não apenas aqueles com deficiência. Tal acepção nos fez inquirir junto aos docentes sobre as inúmeras possibilidades de alargar os conhecimentos advindos da formação para o alcance de outros estudantes também com ritmos, gostos e formas de participação distintas no bojo de nossas práticas pedagógicas. Conforme defendemos, discutir formas de participação de estudantes com deficiência, permite-nos ampliar o alcance de nossas práticas para os demais, também desejosos de currículos e práticas mais convidativas e atentas às suas especificidades (BARBOSA; FIALHO; MACHADO, 2018).

Além da matriz conceitual de estrutura do curso, foram contemplados minicursos com o intuito de proporcionar aos professores cursistas uma formação de problematização das barreiras pedagógicas de acesso e interação ao estudante com deficiência comumente encontradas no contexto da sala de aula comum. Por meio dessa premissa, a organização dos minicursos equivaleu ao conteúdo das Tecnologias Assistivas, como também às seguintes deficiências: visual, intelectual, surdez, Transtorno do Espectro Autista (TEA). Essa escolha decorreu das demandas advindas de estudantes matriculados na rede municipal indicadas em questionários do google forms aplicados com professores cursistas. 


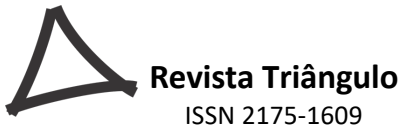

Para os encontros, as formadoras desenvolveram um material educacional digital ${ }^{4}$, o qual os professores cursistas tinham acesso com antecedência no classroom. Geralmente esse material era composto de texto básico, selecionado a partir das literaturas pesquisadas e discutidas com o grupo da coordenação FORESPi. A realização de um grupo de estudo com encontros semanais foi fundante para a organização técnica dos encontros formativos, bem como para trocas da apropriação teórica indispensável à formação.

Acertadamente, o desenho da formação contou metodologicamente com a utilização dos recursos tecnológicos e suas contribuições para/na condução com maior possibilidade de sucesso na FORESPi. A estrutura da formação conquistou a acessibilidade à web pelos professores cursistas e formadoras. A teoria e a prática foram apresentadas e discutidas a partir da interação com as ferramentas disponibilizadas pelo Google, buscando sempre contemplar os professores cursistas e formadores do curso com deficiência, outra peculiaridade da formação.

Assim, o caminho percorrido na formação continuada perpassou o "convite" para "roda de conversas" sobre as temáticas presentes em sua prática pedagógica e relacionados ao processo de inclusão no espaço educacional. Os diálogos aconteciam em grupos com o objetivo de elucidar elementos subjetivos ao processo de ensino e aprendizagem de estudantes com deficiência. Tal como, buscar durante o desenvolvimento dos encontros, estudos dos elementos elucidados como norteadores do fazer pedagógico e da avaliação do trabalho realizado com as crianças/estudantes.

As "conversas" dos encontros contemplaram enquanto estratégias metodológicas: estudos sobre conteúdos teóricos e metodológicos do fazer docente; planejamentos de aulas de modo colaborativo; estudo de caso; e, reflexão dos cotidianos das aulas - decisões sobre o que ensinar, porque ensinar, como ensinar e como avaliar. Essa estratégia possibilitou aos professores o alargamento de suas concepções e práticas pedagógicas calcadas no reconhecimento do outro, suas semelhanças e diferenças.

A avaliação dos encontros aconteceu conforme a caracterização do grupo de professores/cursistas e obedeceu aos seguintes critérios: a participação individual e em grupo nas rodas de conversas com as professoras formadoras; criatividade; análise e avaliação das situações didáticas e pedagógicas visando sempre o ensino e aprendizagem das

\footnotetext{
4 “material educacional digital é todo material didático elaborado com objetivos relacionados à aprendizagem e que incorpora recursos digitais" (Behar, 2009, p.33).
} 
crianças/estudantes com deficiência nas diferentes áreas do conhecimento, numa perspectiva inclusiva.

A atuação dos professores cursistas e envolvimento das formadoras na FORESPI confirmaram a valiosidade da experiência de formação virtual, identificada pela preocupação com a aprendizagem; a motivação para participação; a intensa interação cursista/formador e a escolha de materiais e ferramentas virtuais objeto de alguns dos estilos de aprendizagem no ambiente virtual.

\section{Dos resultados e discussão}

No processo de implementação da FORESPi, a validação da formação docente na modalidade virtual foi efetiva por parte dos professores da aludida rede pública municipal. A adesão dos professores, mediante preenchimento de inscrição via formulário google é um dado importante, afinal:

[...] a formação assume um papel que transcende o ensino que pretende uma mera atualização científica, pedagógica e didática e se transforma na possibilidade de criar espaços de participação, reflexão e formação para que as pessoas aprendam e se adaptem para poder conviver com a mudança e a incerteza. (IMBERNÒN, 2005, p.15).

Ao analisar esse contexto, encontramos algumas evidências passíveis de serem consideradas primordiais na reflexão sobre FORESPi. A primeira, perpassa sobre o trabalho colaborativo e o envolvimento de significativo universo de professores com formações e conhecimentos diversos, ampliando o olhar sobre a proposta de formação e enriquecendo a prática pedagógica a partir das experiências e dos estudos basilares ao escopo teórico da FORESPi.

A formação contou com 10 professoras formadoras e a busca por trazer ao debate a escolarização do estudante com deficiência no âmbito das políticas federais, estaduais e municipais na perspectiva da educação inclusiva. Assim como, pensar um ensino colaborativo no qual professores da sala comum e de Salas de Recursos Multifuncionais (SRM) compartilhem planejamento, intervenções e avaliações, de forma responsável e sem hierarquias (RABELO, 2012). Este último dado refere-se a um aspecto emergente durante a realização dos encontros nas vozes dos professores cursistas e a indicação sobre as dificuldades em estabelecer um trabalho articulado com algumas SRM. 
A segunda evidência a ser considerada refere-se ao conhecimento das necessidades formativas docentes. Aqui, a FORESPi ganha notoriedade pois durante a sua implementação alguns eixos de atuação foram relevantes frente às necessidades formativas docentes, entre estes podemos destacar: a reflexão teórico-prática sobre o cotidiano escolar; a troca de experiências de superação da hierarquia do saber tornando possível a atualização do conhecimento; a intervenção educativa e a comunicação entre os professores; e a formação como estímulo crítico ante práticas sociais como a exclusão.

Considerando as premissas anteriores, a capacidade profissional não se esgota na formação técnica, mas amplia a reflexão dos sujeitos sobre a prática pedagógica realizando um processo de autoavaliação para orientação do trabalho frente aos estudantes com deficiência. A convicção na escuta e no diálogo com professores, portanto, permeou toda sua realização, utilizando estratégias culminantes para práticas pedagógicas alicerçadas no princípio da equidade escolar, social e cultural. Esse pensamento "permitiu acompanhar o desenvolvimento das estratégias inclusivas de educadores em formação, como também provocar a atualização e qualificação tecnológica e pedagógica do currículo do curso de formação" (SANTAROSA; CONFORTO, 2017, p. 242).

A terceira evidência se constituiu pela credibilidade atribuída a FORESPi. O grande interesse acompanhado durante as participações nos encontros e preenchimento de formulários de avaliação, assim como o baixo número de desistência, 26 professores cursistas, fez-nos apostar na credibilidade conferida à proposta. Algumas variáveis podem colaborar para isso, a saber: a carência identificada na rede, haja vista a última proposta formativa ter sido apresentada em 2017 e correspondido a formação de apenas uma turma; a formação inicial e continuada das professoras formadoras todas com cursos em nível lato e stricto sensu acerca do campo de estudos em questão; a versão virtual favorecer a participação conforme disponibilidade/organização de rotina pessoal de cada professor cursista; o interesse em sanar dúvidas com base nas experiências advindas do contato com estudantes com deficiência; obtenção de certificados expedidos pelo órgão gestor do município. Por ora, essas foram as variáveis identificadas, conquanto acreditamos serem emblemáticas as possibilidades de outros aspectos haverem circundado tal credibilidade.

A quarta e última evidência tratou-se da importância de investimentos no âmago das políticas públicas educacionais. As esferas governamentais no âmbito das políticas públicas precisam interagir com os movimentos pedagógicos e metodológicos, bem como as demandas 
da sociedade organizada, mais designadamente, as originadas dos professores no intuito de garantir a qualidade na educação. Com efeito, as mudanças ocorridas ante as propostas para as políticas de formação de professores em todo Brasil não favorecem as indagações sobre o modelo hegemônico para a educação especial (GARCIA, 2011).

Do ponto de vista da conjuntura local do município de realização da FORESPi, alguns dados corroboram para a ênfase ao investimento no cerne das políticas públicas: a política municipal observada e considerada expressão da Política Nacional corrobora para a permanência dos estudantes com deficiência na rede regular de ensino, porém, articula as práticas de formação em atendimento a esses estudantes e seu processo escolar à responsabilidade dos professores da SRM; a estrutura de formação em serviço presente no contexto municipal ainda enfrenta o desafio de aliar o trabalho de professores da SRM e professores da sala comum, privilegiando muitas vezes aos primeiros, para não reforçar pensamentos hegemônicos na escola acerca das deficiências e; a lógica de formação ainda não consegue relacionar uma organização escolar entre o trabalho pedagógico desenvolvido em sala de aula e o trabalho especializado, do ponto de vista das práticas desenvolvidas na esfera municipal.

As nuances apresentadas nos levam a afirmar sobre a necessidade de revisar as propostas de formação docente em curso e vindouras e, nesse sentido, a FORESPi parece consistir em um avanço nas políticas públicas municipais para o rompimento de formações com centralidade na educação especial, ou no Atendimento Educacional Especializado (AEE) como único responsável pela transformação contextual dos estudantes com deficiência.

A FORESPi buscou atuar sobre o preceito do ensino colaborativo entre o professor da sala comum e o professor da SRM e no apoio pedagógico centrado principalmente no estudante com deficiência. Dessa forma, o preceito estabelecido possibilitou uma melhor inclinação ao debate pedagógico mais próximo da escola regular, as dinâmicas curriculares, os processos educativos comuns e uma articulação mais pedagógica à intervenção clínica no processo de escolarização dos sujeitos, até então “[...] distanciados da Educação formal, entre os quais podemos arrolar aqueles identificados com diagnósticos e marcas de deficiência" (GARCIA, 2011, p.68).

\section{CONSIDERAÇÕES FINAIS}


O texto apresentado, além de discutir um corpus teórico acerca da formação docente atrelado ao desafio da inclusão escolar, trouxe como objeto a FORESPi e seus principais resultados. Sua inserção no campo das políticas públicas de formação docente influenciou a relevância da idealização no contexto pandêmico provocado pela Covid 19, ainda no ano de 2020.

A luta pela vida enviesada nas experiências dos professores participantes e formadoras circundou o planejamento da formação como mais uma alternativa de sobrevivência e de manter viva a esperança pelo reencontro com os estudantes em um futuro não muito distante. Desse modo, realçamos o trabalho colaborativo como central ao êxito da formação.

A opção metodológica baseada na diversificação de estratégias enriqueceu os encontros. Seus resultados podem ser reconhecidos em quatro evidências bem demarcadas no decorrer do texto - I. a importância do desenvolvimento de propostas colaborativas no trato da inclusão escolar; II. o relevo ao conhecimento das necessidades formativas docentes; III. a credibilidade atribuída a FORESPi; e a IV. relevância do investimento no âmago das políticas públicas educacionais.

Insistimos nas propostas colaborativas como estratégia de enfrentamento aos contextos de trabalho docente evidenciados pelas largas trajetórias e acúmulo de funções. Trabalhar colaborativamente na FORESPi possibilitou tornar o projeto uma realidade, especialmente pela construção dos princípios teórico e metodológicos cunhados paulatinamente pelo grupo de formadoras e professores cursistas.

Consideramos também a relevância de elaborar estratégias metodológicas para ouvir professores e seus interesses sem desconsiderar as condições de trabalho docente e os limites e possibilidades de ampliação de suas atuações. Por seu turno, a terceira evidência resulta tanto da lacuna na formação dos professores, quanto da confiança depositada nas formadoras, suas formações e clareza em suas argumentações fundamentadas na práxis docente.

Com ênfase, conclamamos a importância da responsabilização de órgãos governamentais na esfera de políticas públicas na correspondência aos interesses docentes. Isso nos adianta o quanto é preciso insistir na promoção de condições para participação dos docentes sem sobrecarregá-los e responsabilizá-los pelo (in)sucesso de suas práticas.

Com o texto, endossamos a formação docente como campo de estudos emblemático e, realçamos a inclusão escolar, nos moldes apresentados, como mais uma via para ampliação de 
nossas lentes de aumento sobre o tema a fim de não compartimentalizar nem o reduzir a um conteúdo distante dos aspectos pedagógicos comuns a outros estudantes sem deficiência.

A inserção do debate acerca da formação docente e o trato de aspectos relativos à inclusão de estudantes com deficiência no contexto da educação geral com suas mazelas e características de um país de origem colonial e escravocrata e as conhecidas dificuldades em oferecer um currículo comum a todos os estudantes, trouxe a oportunidade de descortinar junto aos professores cursistas outras possibilidades de análise a respeito da inclusão desses estudantes sem desconsiderar o contexto amplo de sua inserção.

A afirmação reitera a inclusão escolar como possibilidade de (re)visitarmos nossas práticas e oferecermos condições de participação e desenvolvimento escolar a todos os estudantes, compreendendo as condições enfrentadas no contexto das políticas públicas. Desse modo, cremos oferecer indicativos para o redimensionamento de nossa própria ação, assim como outros estudos, práticas, experiências e pesquisas inspiradas na composição de novos diálogos.

Também alcançou grande reconhecimento, o esforço coletivo de professores da instância municipal, formadoras e cursistas e seus respectivos empenhos a despeito de suas condições pessoais a exemplo da sobrecarga de atividades domésticas, acompanhamento aos estudantes de modo virtual/remoto e os efeitos nefastos da pandemia do ponto de vista econômico, emocional, social, dentre outros.

Outro ponto importante, é a utilização dos recursos tecnológicos pela via da acessibilidade à web pelos professores cursistas e formadoras que enriqueceu a proposta e nos fez inquirir sobre nossas antigas práticas e possibilidades de redimensionamento de propostas formativas ao reconsiderar as condições de trabalho docente. Este, sem dúvida, foi um fator de enriquecimento forçosamente admitido face aos efeitos da pandemia e, felizmente, alcançou eco junto aos participantes.

Em última instância, não menos importante, o texto possibilitou entender as bases teóricas da FORESPi e a insistente ideia acerca da interferência de nossas concepções ao contexto de nossas práticas pedagógicas. Os bastidores compartilhados sob planejamento, metodologia e resultados revelaram condições enfrentadas no espaço educacional em tela.

O estudo, portanto, não teve caráter conclusivo ou prescritivo à prática docente, antes se adiantou como uma rica possibilidade de, em contextos adversos como o enfrentado, (re)criar 
estratégias de interlocução com a escola e seus sujeitos, em especial com suas concepções sobre deficiência e inclusão escolar.

\section{REFERÊNCIAS}

ARAÚJO, N. R. de; CUNHA. C. M. Interpretação do modelo social de deficiência a partir do conceito de normalidade de Canguilhem In: Conjectura: Filos. Educ., Caxias do Sul, RS, v. 25, Dossiê, 2020. http://dx.doi.org/10.18226/21784612.v25.dossie.18 Disponível em: http://www.ucs.br/etc/revistas/index.php/conjectura/article/view/7588/pdf Acesso em: 31 mar. 2021.

BARBOSA, D. de S.; FIALHO; L. M. F.; MACHADO, C. J. dos. Educação inclusiva: aspectos históricos, políticos e ideológicos da sua constituição no cenário internacional. In: Revista Electrónica Actualidades Investigativas en Educación. Volumen 18 Número 2, Año 2018, ISSN 1409-4703. https://doi.org/10.15517/aie.v18i2.33213 Disponível em: https://www.scielo.sa.cr/pdf/aie/v18n2/1409-4703-aie-18-02-598.pdf Acesso em 31 mar. 2021.

BEHAR, P. A. (orgs.). Modelos pedagógicos em educação à distância. Porto Alegre: Artmed, 2009.

BRASIL. Política Nacional de Educação Especial na perspectiva da Educação Inclusiva. Secretaria de Educação Especial, Brasília: MEC / SEF/SEESP, 2008.

BUENO, J. G. As políticas de inclusão escolar: uma prerrogativa da educação especial? In: BUENO, J. G.; MENDES, G.; SANTOS, R. Deficiência e escolarização: novas perspectivas de análise. Brasília: Junqueira \& Marin, 2008, p. 43-63.

DINIZ-PEREIRA, J. E. A construção do campo da pesquisa sobre formação de professores.

In: Revista da FAEEBA - Educação e Contemporaneidade, Salvador, v. 22, n. 40, p. 145154, jul./dez. 2013. https://doi.org/10.21879/faeeba2358-0194.2013.v22.n40.p145-154

Disponível em: https://www.revistas.uneb.br/index.php/faeeba/article/view/7445 Acesso em: 30 mar. 2021.

DINIZ, D.; BARBOSA, L.; SANTOS, W. R. dos. Deficiência, Direitos Humanos e Justiça. Sur. Revista Internacional de Direitos Humanos, v. 6, n. 11, p. 65-77, dez. 2009. https://doi.org/10.1590/S1806-64452009000200004 Disponível em: https://www.scielo.br/scielo.php?script=sci_arttext\&pid=S1806-64452009000200004 Acesso em: 18 mar. 2021. FERREIRA, M. C. C.; FERREIRA, J. R. Sobre Inclusão, Políticas Públicas e Práticas Pedagógicas. In: GÓES, M. C. R. de; LAPLANE, A. F. de (Orgs.). Políticas e práticas de educação inclusiva. Campinas, SP: Autores Associados, 2004, p 21-48. (Coleção educação contemporânea.)

FREITAS, H. C. L. Dez anos de LDB: tensões e contradições na formação dos profissionais da educação. In: SOUZA, J. V. A de. Formação de Professores para a Educação Básica: Dez anos da LDB. Belo Horizonte: Autêntica, 2007, p. 143-158.

GARCIA, R. M. C. Política Nacional de Educação Especial nos anos 2000: a formação de professores e a hegemonia do modelo especializado. In: CAIADO, K.R.M.; JESUS, D. M. de; BAPTISTA, C. R. (Orgs.) Professores e Educação Especial: formação em foco. Porto Alegre: Mediação/CDV/FACITEC, 2011.

GAUDENZI, P.; ORTEGA; F. Problematizando o conceito de deficiência a partir das noções de autonomia e normalidade. In: Ciênc. saúde colet. 21, out 2016. 
https://doi.org/10.1590/1413-812320152110.16642016 Disponível em:

https://www.scielo.br/scielo.php?script=sci_arttext\&pid=S1413-

81232016001003061\&lng=pt\&tlng=pt Acesso em: 12 fev. 2021.

IMBERNÓN, Francisco. Formação Docente e Profissional: formar-se para a mudança e a incerteza. $5^{\mathrm{a}}$ ed. São Paulo, Cortez, 2005.

KASSAR, M. de C. M. Matrículas de crianças com necessidades educacionais na rede de ensino regular: do que e de quem se fala?. In: GÓES, M. C. R. de; LAPLANE, A. F. de (Orgs.). Políticas e práticas de educação inclusiva. Campinas, SP: Autores Associados, 2004. p. 49-68. (Coleção educação contemporânea.)

LAPLANE, A. Notas para uma Análise dos Discursos sobre Inclusão Escolar. GÓES, M. C. R. de; LAPLANE, A. F. de (Orgs.). Políticas e práticas de

educação inclusiva. Campinas, SP: Autores Associados, 2004. p. 5-20. (Coleção educação contemporânea.)

NASCIMENTO, M. das G. C. de A.; REIS, R. F. dos. Formação docente: percepções de professores ingressantes na rede municipal de ensino do Rio de Janeiro. In: Educ. Pesqui., São Paulo, v. 43, n. 1, p. 49-64, jan./mar. 2017. http://dx.doi.org/10.1590/S1517-

9702201701150846 Disponível em:

https://www.scielo.br/scielo.php?script=sci_arttext\&pid=S1517-

97022017000100049\&lng=pt\&tlng=pt Acesso em: 13 fev. 2021.

PAIVA, J. C. V.; BENDASSOLLI, P. F. Políticas sociais de inclusão social para pessoas com deficiência. In: Psicologia em Revista, Belo Horizonte, v. 23, n. 1, p. 418-429, jan. 2017. http://dx.doi.org/10.5752/P.1678-9563.2017v23n1p418-429 Disponível em:

http://periodicos.pucminas.br/index.php/psicologiaemrevista/article/view/16701Acesso em: 10 fev. 2021.

RABELO, L. C. C. Ensino colaborativo como estratégia de formação continuada de professores para favorecer a inclusão escolar. São Carlos. UFSCar, 2012.

SANTAROSA, L. M. C.; CONFORTO, Debora. A equidade da formação docente na modalidade a distância. In: Revista de Educação, Porto Alegre, v. 40, n. 2, p. 240-249, maioago. 2017. http://dx.doi.org/10.15448/1981-2582.2017.2.22943

Disponível em: https://revistaseletronicas.pucrs.br/ojs/index.php/faced/article/view/22943

Acesso em: 25 mar. 2021.

SILVEIRA, F. da R.; CASTAMAN, A. S. Formação continuada de profissionais da educação: problematizações na educação profissional e tecnológica. In: Revista de Estudos e Pesquisas sobre Ensino Tecnológico, v. 6, 2020. https://doi.org/10.31417/educitec.v6i.934

Disponível em: https://sistemascmc.ifam.edu.br/educitec/index.php/educitec/article/view/934 Acesso em: 31 mar. 2021.

VASCONCELLOS, C. dos S. Planejamento: projeto de ensino-aprendizagem e projeto político-pedagógico- elementos para elaboração e realização. São Paulo: Libertad Editora, 2006.

VÓVIO, C. L; ALMEIDA, R. Formação de professores: os desafios da profissão [online].

SciELO em Perspectiva: Humanas, 2019 [viewed 30 March 2021]. Disponível em: https://humanas.blog.scielo.org/blog/2019/01/30/formacao-de-professores-os-desafios-daprofissao/ Acesso em: 31 mar. 2021. 